\title{
Comparative actinomycete diversity in marine sediments
}

\author{
Alejandra Prieto-Davó, William Fenical, Paul R. Jensen* \\ Center for Marine Biotechnology and Biomedicine, Scripps Institution of Oceanography, University of California San Diego, \\ La Jolla, California, 92093-0204, USA
}

\begin{abstract}
The diversity of cultured actinomycete bacteria was compared between near- and offshore marine sediments. Strains were tested for the effects of seawater on growth and analyzed for 16S rRNA gene sequence diversity. In total, 623 strains representing 6 families in the order Actinomycetales were cultured. These strains were binned into 16 to 63 operational taxonomic units (OTUs) over a range of 97 to $100 \%$ sequence identity. The majority of the OTUs were closely related (>98\% sequence identity) to strains previously reported from non-marine sources, indicating that most are not restricted to the sea. However, new OTUs averaged 96.6\% sequence identity with previously cultured strains and ca. one-third of the OTUs were marine-specific, suggesting that sediment communities include considerable actinomycete diversity that does not occur on land. Marine specificity did not increase at the off-shore sites, indicating high levels of terrestrial influence out to $125 \mathrm{~km}$ from shore. The requirement of seawater for growth was observed among $<6 \%$ of the strains, while all members of 9 OTUs possessed this trait, revealing a high degree of marine adaptation among some lineages. Statistical analyses predicted greater OTU diversity at the off-shore sites and provided a rationale for expanded exploration of deep-sea samples. A change in community composition was observed, with the number of Micromonospora OTUs increasing in the off-shore samples. UniFrac (see http://bmf2.colorado.edu/unifrac) statistics support a difference in community composition between near- and off-shore locations. Overall, 123 of 176 strains had distinct 16S rRNA gene sequences, indicating a high level of actinomycete diversity in marine sediments.
\end{abstract}

KEY WORDS: Marine actinomycetes · Marine sediments • Bacterial diversity · Seawater requirements · Phylogeny

\section{INTRODUCTION}

Bacteria belonging to the order Actinomycetales, commonly called actinomycetes, represent one of the most studied and exploited classes of bacteria due to their ability to make a wide range of biologically active metabolites (Goodfellow et al. 1988, Bull et al. 2000). These microorganisms have been recovered from diverse environments including rain forests (Wang et al. 1999), lake sediments (Terkina et al. 2002), estuaries (Takizawa et al. 1993), and deep ocean trenches (Colquhoun et al. 1998). With respect to the marine environment, it has long been known that actinomycetes can be cultured from ocean samples including sediments collected at depths $>3 \mathrm{~km}$ (Weyland 1969).
Marine-derived strains have more recently received attention as a resource for biotechnology (Bull et al. 2005, Fiedler et al. 2005). To date, taxonomic studies of marine-derived actinomycetes have led to the description of 3 new genera: Salinibacterium, Serinicoccus and Salinispora (Han et al. 2003, Yi et al. 2004, Maldonado et al. 2005a), the proposal of Solwaraspora as a fourth (Magarvey et al. 2004), and various new species (e.g. Helmke \& Weyland 1984, Stach et al. 2004). These studies have made it clear that new taxa reside in the ocean; however, the extent to which actinomycete communities differ between the land and sea remains unknown.

Although actinomycetes are regularly recovered from marine samples, they are also common soil inhab- 
itants and are undoubtedly transported in large numbers from land into the sea. Considering that many species are salt tolerant and produce spores (Basilio et al. 2003), it is not surprising that some strains recovered from near-shore marine samples also occur on land (e.g. Gontang et al. 2007). To date, the component of the marine actinomycete community that appears to be specific to the marine environment has not been defined for any environmental samples. It has also yet to be determined which members of these communities are metabolically active in marine sediments (Goodfellow \& Haynes 1984), although evidence of marine adaptation and growth in the marine environment has been reported (Moran et al. 1995, Mincer et al. 2002).

In an effort to gain a better understanding of marine actinomycete community composition, strains isolated form marine sediments collected near-shore $(\leq 2 \mathrm{~km}$ from shore) were analyzed and compared to those isolated from samples collected 30 to $125 \mathrm{~km}$ from shore (off-shore). One goal was to test the hypothesis that the number of marine-specific strains would increase at sites more distant from shore, where terrestrial input was presumed to be less. The requirement of seawater for growth was also assessed as an indicator of marine adaptation and to determine if this trait could be used as a tool to enhance the recovery of new marine taxa. The results indicated that new actinomycete phylotypes can readily be cultured from marine samples, yet differences in community structure between near- and off-shore sites could not be linked to marine-specificity or seawater dependence.

\section{MATERIALS AND METHODS}

Sample collection and processing. Fifty-seven nearshore marine sediment samples were collected using a modified surface-deployed grab sampler (model \#214WA110, Kahlsico) from a depth range of 30 to $150 \mathrm{~m}$ within a $0.5 \mathrm{~km}^{2}$ quadrant centered $1.8 \mathrm{~km}$ off the coast of La Jolla, California, USA $\left(32^{\circ} 53.01^{\prime} \mathrm{N}\right.$, $117^{\circ} 16.22^{\prime}$ W) in August, September, and November 2001. Eleven off-shore San Diego sediment samples were collected from 6 different locations along an $85 \mathrm{~km}$ transect $\left(32^{\circ} 39.75^{\prime} \mathrm{N}, 117^{\circ} 16.083^{\prime} \mathrm{W}\right.$ to $32^{\circ} 11.09^{\prime} \mathrm{N}, 118^{\circ} 18.02^{\prime} \mathrm{W}$ ) that extended to $125 \mathrm{~km}$ from shore. These samples were collected using an untethered coring device designed and constructed at the Scripps Institution of Oceanography (SIO) from which cores 20 to $30 \mathrm{~cm}$ in length were obtained. When possible, the cores were separated into 2 to 6 sections (ca. $5 \mathrm{~cm}$ each). Five additional off-shore samples were obtained from a $55 \mathrm{~km}^{2}$ region that extended from $32 \mathrm{~km}$ off the Farallon Islands out to $60 \mathrm{~km}$ off the coast of San Francisco $\left(37^{\circ} 39.998^{\prime} \mathrm{N}, 123^{\circ} 27.001^{\prime} \mathrm{W}\right.$ to $37^{\circ} 42.946^{\prime} \mathrm{N} 123^{\circ} 32.947^{\prime} \mathrm{W}$ ). All near-shore samples were placed in sterile $50 \mathrm{ml}$ centrifuge tubes using an ethanol-sterilized spatula and transported to the SIO for processing (generally within $4 \mathrm{~h}$ ). For the off-shore San Diego samples, core sections were placed in sterile Petri dishes and kept at $4^{\circ} \mathrm{C}$ prior to processing (generally within $1 \mathrm{wk}$ ). The San Francisco samples were collected using a $0.25 \mathrm{~m}^{2}$ box corer (Sandia MKIII, Ocean Instruments) and approximately $10 \mathrm{ml}$ of wet sediment was removed from the surface of each core using an alcohol sterilized stainless steel spoon, placed in sterile $50 \mathrm{ml}$ centrifuge tubes, and maintained at $4{ }^{\circ} \mathrm{C}$ for approximately $2 \mathrm{wk}$ before being processed.

All samples were processed using previously described heat-shock and drying methods (Mincer et al. 2002) and inoculated onto medium M1 (10 g starch, $4 \mathrm{~g}$ yeast extract, $2 \mathrm{~g}$ peptone, $18 \mathrm{~g}$ agar, $1 \mathrm{l}$ of natural seawater). Medium M1 was amended with cycloheximide $\left(100 \mu \mathrm{g} \mathrm{ml}^{-1}\right.$ final concentration) and either rifamycin (5 $\mathrm{g} \mathrm{m} \mathrm{ml}^{-1}$ final concentration) or gentamicin (10 $\mu \mathrm{g} \mathrm{ml}^{-1}$ final concentration). Briefly, for the heatshock method, $1 \mathrm{ml}$ of wet sediment was added to $4 \mathrm{ml}$ of sterile seawater (for San Diego off-shore samples, $2 \mathrm{ml}$ of wet sediment was used), heated for $6 \mathrm{~min}$ at $55^{\circ} \mathrm{C}$, vigorously shaken, further diluted $(1: 100$ and 1:1000) in sterile seawater, and $50 \mu \mathrm{l}$ of each dilution was inoculated onto medium M1 by spreading with a sterile glass rod. For the stamping method, approximately $10 \mathrm{ml}$ of wet sediment was aseptically placed into a sterile petri dish and dried (ca. $24 \mathrm{~h}$ ) in a laminar flow hood. A sterile foam plug (14 mm diameter) was pressed into the dried sediment and used to inoculate the medium by stamping 8 or 9 times in a circular fashion, giving a serial dilution effect. Due to the low yield of actinomycete colonies obtained from the San Diego off-shore sediments, these samples were also stamped onto $1 / 4$ th and $1 / 8$ th strength M1 medium.

Actinomycetes were recognized based on colony and microscopic morphology. Colonies with a tough leathery texture, dry or folded appearance, and branching filaments with or without aerial hyphae that could be observed either unaided by eye or using a dissecting microscope $(64 \times$ magnification) were transferred from the primary plates onto new media. Hence, this study was limited to filamentous bacteria within the order Actinomycetales. An attempt was made to obtain in pure culture all accessible actinomycete-like colonies observed on the plates. Actinomycetes from near-shore sediments generally appeared after 2 to 6 wk of incubation at 25 to $28^{\circ} \mathrm{C}$, while colonies from the off-shore samples took 8 to $12 \mathrm{wk}$ to appear.

Effects of seawater on growth. All strains were tested for the effects of seawater on growth using medium M1 prepared with either seawater or de- 
ionized water. A single colony from each isolate was carefully transferred from a culture growing on medium M1 (seawater) and dilution streaked onto plates of the same medium prepared with either seawater or de-ionized water. In cases where only a few colonies appeared on the de-ionized water plates, the process was repeated using one of these colonies to ensure that growth was not due to salts carried over from the initial transfer. Based on the results of these tests, strains were categorized as either seawater dependent (no growth on M1/de-ionized water) or non-seawater dependent (growth on both media). The number of strains for which the relative amount of visually assessed growth was reduced in the absence of seawater was also recorded.

16S rRNA gene amplification and sequencing. The PCR amplification of the 16S rRNA gene was carried out with primers FC27 (5' to 3' AGAGTTTGATCCTGGCTCAG) and RC1492 (5' to 3' TACGGCTACCTTGTTACGACTT). PCR products were purified using a Qiagen QIAquick PCR cleanup kit using the manufacturer's protocols (Qiagen). Partial gene sequences were obtained using the FC27 primer, and nearly full sequences (1484 bp, Escherichia coli positions 8 to 1492) in both the forward and reverse directions were obtained for select strains using the additional sequencing primers F514 (5' to 3' GTGCCAGCAGCC GCGGTAA), F1114 (5' to 3' GCAACGAGCGCAA CCC), RC1492 (5' to 3' TACGGCTACCTTGTTACGA CTT), R936 (5' to $3^{\prime}$ GTGCGGGCCCCCGTCAATT), and R530 (5' to 3' CCGCGGCTGCTGGCACGTA). Forward and reverse strand contigs were assembled using Sequencher (version 4.5, Gene Codes).

Phylogenetic analysis. Partial and nearly complete 16S rRNA gene sequences were analyzed using the Basic Local Alignment Search Tool (BLAST) (Altschul et al. 1990) on the NCBI website (www.ncbi.nlm.nih. gov/) and the percent identity of each sequence to the closest cultured strain recorded. Operational taxonomic units (OTUs) were calculated for all partial sequences (573 bp near-shore, 642 bp off-shore) at 97 , 98,99 , and $100 \%$ sequence identity using the program Clusterer (www.bugaco.com/mioritic/clusterer_jlp.php) by setting the distance parameter to the number of nucleotides required to give the desired consensus groups. If all of the strains in an OTU shared $\leq 98 \% 16 \mathrm{~S}$ rRNA gene sequence identity with any previously cultured strain for which sequence data was available, it was defined as a 'new' OTU. OTUs were otherwise considered 'known' or, if all NCBI sequence deposits sharing $>98 \%$ sequence identity to strains within an OTU were from marine sources, the OTU was further considered 'known marine'. One representative of each OTU in the $98 \%$ consensus group was selected for nearly complete $16 \mathrm{~S}$ rRNA gene sequencing. As- sembled sequences were imported into the ARB database (www.arb-home.de/), automatically then manually aligned along with their closest BLAST matches, and exported into PAUP (Swofford 2002) for phylogenetic analysis. Neighbor-joining distance trees were created using 1378 base pairs and default settings with uncorrected ' $\mathrm{p}$ '. Bootstrap analyses were performed with 1000 re-samplings.

Statistical analyses. Non-parametric diversity estimators as well as Shannon and Simpson indexes were calculated using EstimateS (Version 7, Colwell 2004 http://purl.oclc.org/estimates). For the 111 near-shore strains sequenced, coverage was calculated using the equation: $C=1-(n / N) \times 100$, where $n=$ number of unique OTUs and $N=$ total number of OTUs examined (Good 1953). The UniFrac web tool (http://bmf2. colorado.edu/unifrac/index.psp) is a multivariate statistic that was employed to further analyze and compare the phylogenetic diversity between the near- and off-shore actinomycete communities.

\section{RESULTS}

Fifty-seven near-shore marine sediment samples were collected at depths of 30 to $150 \mathrm{~m}$ and distances of 1.5 to $2.0 \mathrm{~km}$ off the coast of San Diego (Table 1). Sixteen additional samples were collected from 2 offshore locations (depths 1.1 to 3.1 and 30 to $125 \mathrm{~km}$ from shore); 11 of these came from a site off San Diego and 5 from a site off San Francisco (Table 1). All 73 samples were processed for the selective cultivation of actinomycete bacteria and an attempt was made to obtain in pure culture all accessible actinomycete colonies observed on the isolation plates.

In total, 623 actinomycete strains were isolated, the vast majority of which (557) were obtained from the near-shore locations (Table 1). Although more samples were collected from the near-shore sites, they yielded ca. 2 and 5 times as many strains per sample as the offshore San Diego and San Francisco sites, respectively. Of the 623 strains cultured, $32(5.1 \%)$ required seawater for growth, while $39(6.3 \%)$ showed reduced growth when seawater was replaced with de-ionized water in the culture medium. All strains for which the absence of seawater in the culture medium affected growth originated from the near-shore samples. The vast majority $(88.3 \%)$ of the actinomycetes cultured grew equally well when seawater was replaced with de-ionized water in the cultivation medium.

Partial 16S rRNA gene sequences were obtained for all of the strains isolated from samples collected offshore San Diego (57 strains) and San Francisco (9 strains) (Table 1). For the near-shore samples, 111 strains were selected for sequencing based on their 
Table 1. Marine sediment sampling sites, ocean depths, distances from shore, number of actinomycetes isolated, and the effects of seawater on growth. NA: not applicable

\begin{tabular}{|c|c|c|c|c|c|c|c|c|}
\hline \multirow[t]{2}{*}{ Site } & \multirow[t]{2}{*}{$\begin{array}{c}\text { Depth } \\
(\mathrm{km})\end{array}$} & \multirow[t]{2}{*}{$\begin{array}{c}\text { Distance } \\
(\mathrm{km})\end{array}$} & \multirow[t]{2}{*}{$\begin{array}{c}\text { No. } \\
\text { samples }\end{array}$} & \multirow[t]{2}{*}{$\begin{array}{c}\text { Strain isolated } \\
\text { (sequenced) }\end{array}$} & \multirow[t]{2}{*}{$\begin{array}{l}\text { Strains per } \\
\text { sample }\end{array}$} & \multicolumn{3}{|c|}{$\begin{array}{l}\text { Seawater } \\
\text { requirement }\end{array}$} \\
\hline & & & & & & Yes & No & $\mathrm{No}^{\mathrm{a}}$ \\
\hline \multicolumn{9}{|l|}{ San Diego } \\
\hline Near-shore & $0.03-0.15$ & $1.5-2.0$ & 57 & 557 (111) & 9.8 & 32 & 486 & 39 \\
\hline Off-shore ${ }^{b}$ & $1.1-2.0$ & $30-125$ & 11 & $57(57)$ & 5.2 & 0 & 56 & 0 \\
\hline \multicolumn{9}{|l|}{ San Francisco } \\
\hline Off-shore & $2.3-3.1$ & $32-40^{\mathrm{c}}$ & 5 & $9(9)$ & 1.8 & 0 & 8 & 0 \\
\hline Total & NA & NA & 73 & $623(177)$ & 8.5 & 32 & 550 & 39 \\
\hline
\end{tabular}

response to the replacement of seawater with de-ionized water in the growth medium. These included all 32 strains that required seawater for growth, all 39 strains that displayed reduced growth without seawater, and 40 randomly chosen strains that grew equally well on both media. In total, partial 16S rRNA gene sequence data were obtained for 177 of the 623 strains obtained in culture.

Given that various 16S rRNA gene sequence identity values have been used to assess species-level diversity (e.g. Hagström et al. 2002), OTUs were calculated over a range from 97 to $100 \%$ sequence identity. These analyses resulted in the detection of 18 to 60 OTUs from the near-shore sediments and 16 to 63 OTUs from the off-shore sediments (Table 2). In near-shore sediments, new OTUs ranged from 17 to $32 \%$ of the total while in off-shore sediments the range was 16 to $25 \%$ (Table 2). On average for all sequence identity groups, $26 \%$ of the near-shore and $20 \%$ of the off-shore OTUs were new to this study. In all but the $97 \%$ consensus group, new OTUs were more common in the nearshore samples. Known marine OTUs ranged from 6 to $12 \%$ of the various near-shore and from 12 to $16 \%$ of the various off-shore consensus group totals (Table 2). Overall, the number of OTUs recovered in this study that are marine specific (i.e. have only been reported from marine sources) averaged $35 \%$ over all consensus groups for the near-shore samples and $32 \%$ for the offshore samples. All of the new OTUs recovered from the off-shore San Diego samples originated from the 5 to $10 \mathrm{~cm}$ sections of the cores (data not shown), supporting the need for further studies of vertical actinomycete profiles in marine sediments. Only 2 strains were isolated from below the top $10 \mathrm{~cm}$ of any core despite the fact that actinomycetes have been detected down to $46 \mathrm{~cm}$ when culture-independent techniques were applied to a deep-sea core (Stach et al. 2003).

Based on BLAST analyses of partial 16S rRNA gene sequence data, the 177 strains sequenced were most closely related to 8 genera (Table 3 ). The majority of these $(85 \%)$ were affiliated with the genus Streptomyces (108 strains) or Micromonospora (42 strains). The relative abundance of Micromonospora to Streptomyces strains increased by greater than 10-fold in the off-shore San Diego sites. Both near- and off-shore sediments yielded 1 to 3 strains related to the genera Actinomadura, Saccharomonospora, and Verrucosispora, while Nocardiopsis, Streptomonospora, and Streptosporangium were only recovered from sediments collected near-shore. Of the 5 OTUs, 2 belong-

Table 2. Number of operational taxonomic units (OTUs) recovered from near-shore (NS) and off-shore (OS) marine sediments calculated using consensus groups ranging from 97 to $100 \%$ 16S rRNA gene sequence identity (\% of total given in parentheses). OTUs were identified as new if all strains shared $\leq 98 \% 16 \mathrm{~S}$ rRNA gene sequence identity with previously cultured strains for which sequence data were available. Otherwise, OTUs were considered known (previously cultured), or known marine (previously cultured from marine sources)

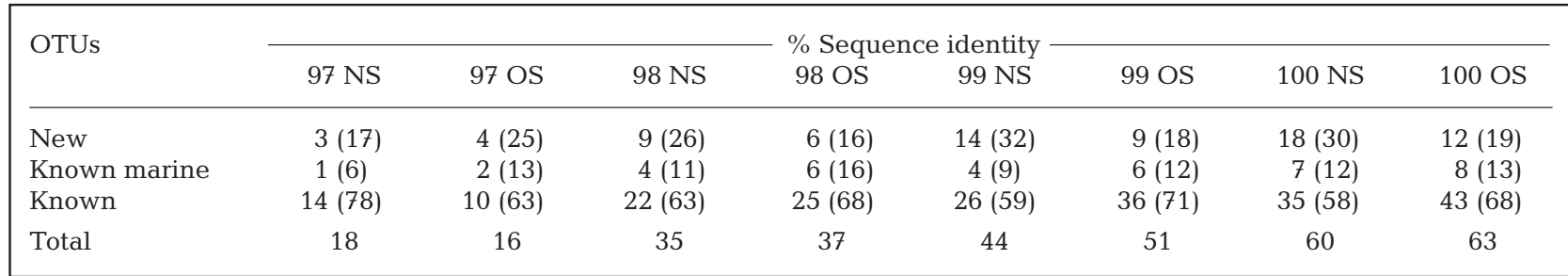


Table 3. Generic affiliation and abundance of actinomycete strains and OTUs recovered from near and off-shore samples as delineated by 98\% 16S rRNA gene sequence identity. Number of new OTUs are given in parentheses and those requiring seawater for growth in italics. Total number of unique OTUs off-shore OTU represented by CNS-635 [Fig. 2b] is shared between San Diego and San Francisco)

\begin{tabular}{|c|c|c|c|c|c|c|}
\hline \multirow[t]{3}{*}{ Genus } & \multicolumn{4}{|c|}{ San Diego } & \multirow{2}{*}{\multicolumn{2}{|c|}{$\begin{array}{c}\text { San Francisco } \\
\text { Off-shore }\end{array}$}} \\
\hline & \multicolumn{2}{|c|}{ Near-shore } & \multicolumn{2}{|c|}{ Off-shore } & & \\
\hline & Strains & OTUs & Strains & OTUs & Strains & OTUs \\
\hline Actinomadura & 1 & 1 & 0 & 0 & 1 & 1 \\
\hline Micromonospora & 11 & 5 & 31 & 15, (1) & 0 & 0 \\
\hline Nocardiopsis & 9 & $2,(1), 2$ & 0 & 0 & 0 & 0 \\
\hline Saccharomonospora & 3 & 1,1 & 1 & 1 & 0 & 0 \\
\hline Streptomonospora & 5 & $2,(1), 2$ & 0 & 0 & 0 & 0 \\
\hline Streptomyces & 79 & $22,(7), 4$ & 22 & $12,(3)$ & 7 & $7,(2)$ \\
\hline Streptosporangium & 1 & 1 & 0 & 0 & 0 & 0 \\
\hline Verrucosispora & 2 & 1 & 3 & 1 & 1 & 1 \\
\hline Total & 111 & $35,(9), 9$ & 57 & 29, (4) & 9 & $9,(2)$ \\
\hline
\end{tabular}
among the 3 sampling sites is 54 and between the 2 off-shore sites is 37 (i.e. 1

$(18 \%)$ within the $97 \%$ consensus group (Fig. 1). There was no evidence for an increase in the probability of an OTU being new or 'known marine' based on the requirement of seawater for growth (T-test of proportions, $\mathrm{p}=$ 0.2505). Each of the 4 sequence identity groups (97 to $100 \%$ ) contained 3 or 4 OTUs in which the requirement of seawater for growth varied among strains. All of these 'variable' OTUs were observed in the near-shore samples, affiliated with the genus Streptomyces, and in most cases only reported from marine sources. Of the 9 seawater-requiring OTUs identified within the $98 \%$ consensus group (Table 3), 5 were previously reported form non-marine sources.

Representatives of the 35 near-shore ing to these latter 3 groups were new to this study (Table 3). The OTU to sample ratio was considerably higher for off-shore (38:16) compared to near-shore samples (35:57), yet the total number of genera observed was greater in the near-shore samples (8 vs. 5) as was the number of strains per OTU (3.2 vs. 1.7). BLAST identity scores for all strains ranged from 91.3 to $100 \%($ mean $=98.4 \pm 1.4 \%)$ and averaged $96.6 \%$ for the strains in the new OTUs (98\% consensus group).

Considering the total diversity observed in this study, the number of OTUs in which all strains required seawater for growth ranged from 14 of 126 $(11 \%)$ within the $100 \%$ consensus group to 6 of 34

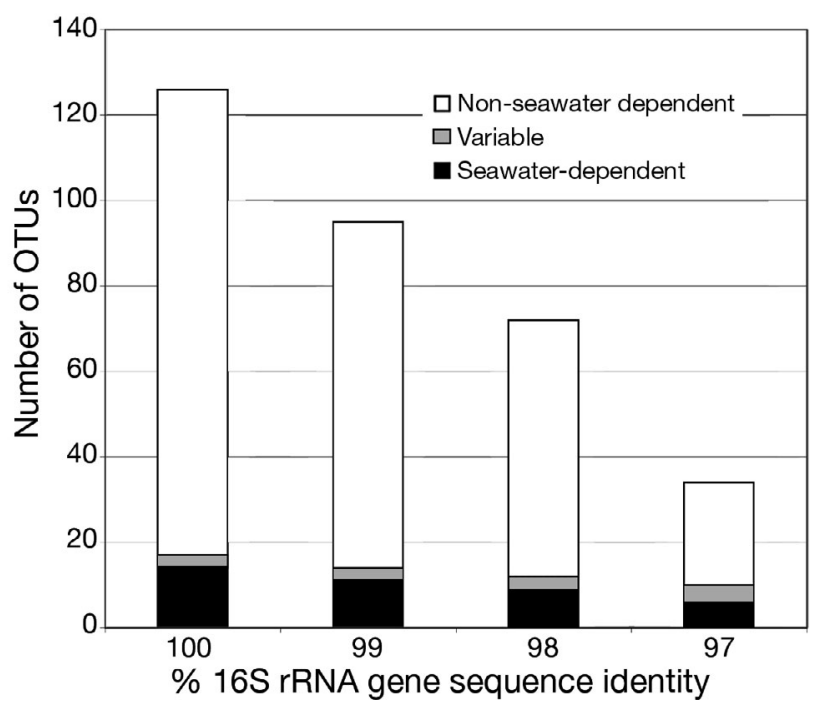

Fig. 1. Number of seawater-dependent, non-seawater-dependent, and variable operational taxonomic units (OTUs) at consensus groups ranging from 97 to $100 \%$ for combined near- and off-shore data sets and 37 off-shore OTUs delineated at 98\% sequence identity (Table 2 ) were chosen for nearly complete $16 \mathrm{~S}$ rRNA gene sequencing and phylogenetic analysis (Fig. 2). The increased abundance and diversity of Micromonospora relative to Streptomyces in the offshore communities is evident when comparing the trees generated from these 2 sites. New OTUs are scattered throughout the near-shore tree (Fig. 2a), while at the off-shore sites new diversity is restricted to the genus Streptomyces with the exception of one Micromonopora OTU. Among the near-shore strains, 2 distinct marine clades related to the genus Streptomyces are evident (Fig. 2a). The clade at the top of the tree comprises 24 strains that fall into 5 OTUs, 3 of which are new. All OTUs within this clade and all NCBI reference strains that share $>98 \%$ sequence identity were derived from marine sources, making this a highly diverse marine lineage within the genus Streptomyces. Seventeen strains belonging to this clade were also isolated from the off-shore samples (Fig. 2b, represented by strain CNS-775). These strains fall into 9 OTUs, all of which are marine and 3 of which are new. There is strong bootstrap support for the delineation of the second marine clade represented by strain CNQ-259. Members of this group, which have previously been referred to as MAR2, were also observed in both the near- and off-shore communities. The relationship of MAR2 as a sister lineage to the genus Streptomyces indicates that it may represent a new genus. This clade has proven to be a rich source of macrolide antibiotics (Fenical \& Jensen 2006).

Seawater-requiring OTUs belonging to clades related to the genera Streptomonospora and Nocardiopsis were also observed (Fig. 2a). Interestingly, the most closely related reference strains are either 

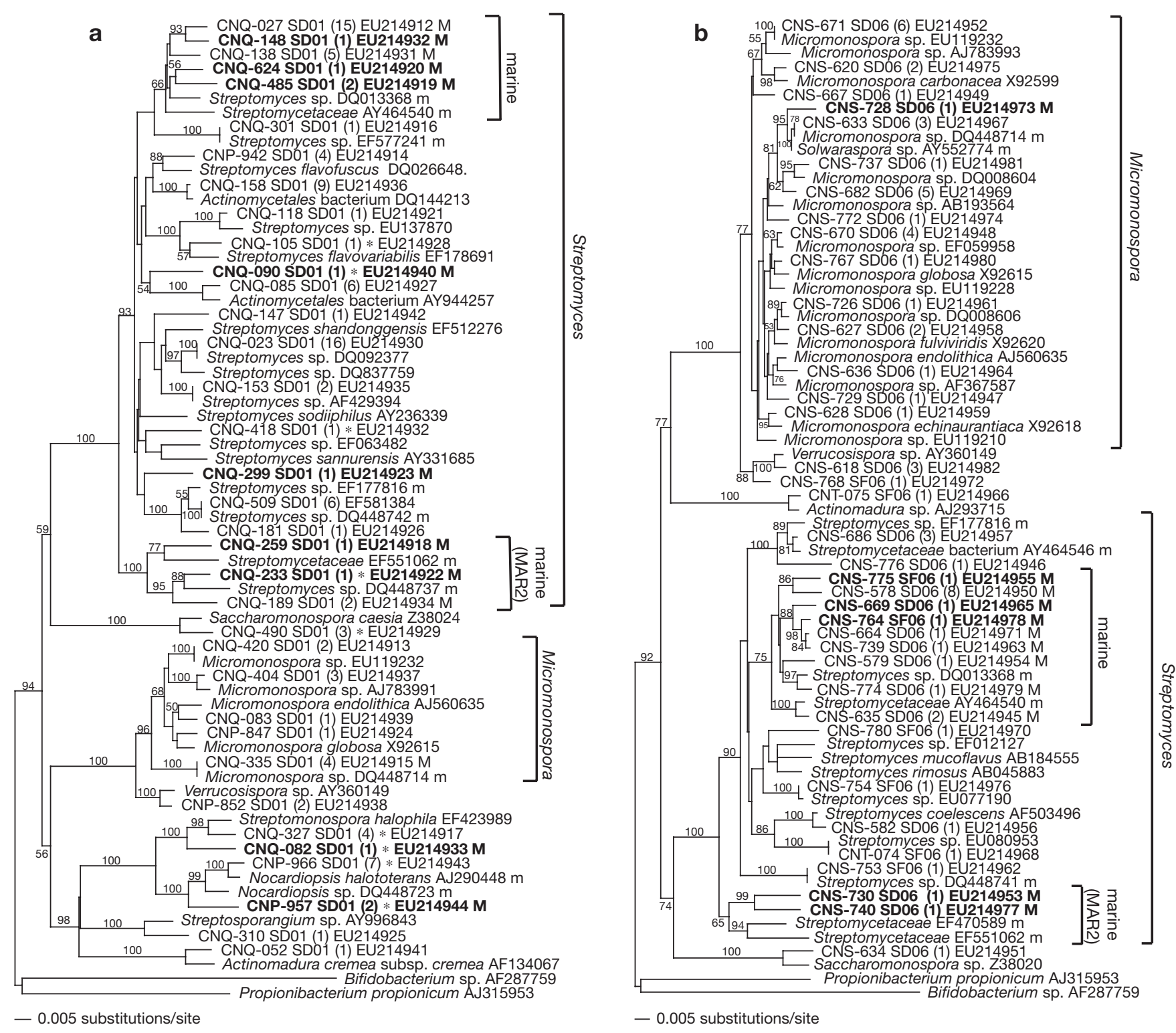

Fig. 2. Neighbor-joining distance trees detailing the phylogenetic relationships among OTU representatives (based on $98 \%$ sequence identity, $1378 \mathrm{bp}$ ) cultured from (a) near-shore and (b) off-shore marine sediments. The closest BLAST matches to each OTU are included with strain name and GenBank accession number. OTU representatives are shown with strain number (e.g. CNQ-082), collection location (SD = San Diego, SF = San Francisco), and year (e.g. $01=2001)$. The number of strains in each OTU is presented in parentheses. Bold $=$ new OTUs, $*=$ seawater-dependent OTUs, italics $=$ variable OTUs (i.e. OTUs containing both seawater-dependent and non-dependent strains), $M=$ marine OTUs (all NCBI reference sequences sharing $>98 \%$ sequence identity are from marine sources), $\mathrm{m}$ = reference sequence derived from a marine source. Propionibacterium propionicum and Bifidobacterium sp. were used to root the trees. Bootstrap values greater than 50 are placed at their respective nodes

from marine or high salt environments. Three additional seawater-requiring OTUs are scattered throughout the genus Streptomyces (Fig. 2a). All but one of these (CNQ-090) is associated with an OTU that has also been reported from non-marine sources. One additional seawater-requiring OTU is related to the genus Saccharomonospora. None of the OTUs from the genus Micromonospora required seawater for growth, while the related, seawater-dependent genus Salinispora, which has been consistently cultured from tropical and subtropical sediments (Jensen \& Mafnas 2006), was not observed despite the use of cultivation methods known to support the growth of this taxon.

Using the OTUs delineated at $98 \%$ sequence identity, the percent coverage $(C)$ of the near-shore collection was calculated to be $74 \%$, suggesting that the diversity within the 557 -strain collection was well 


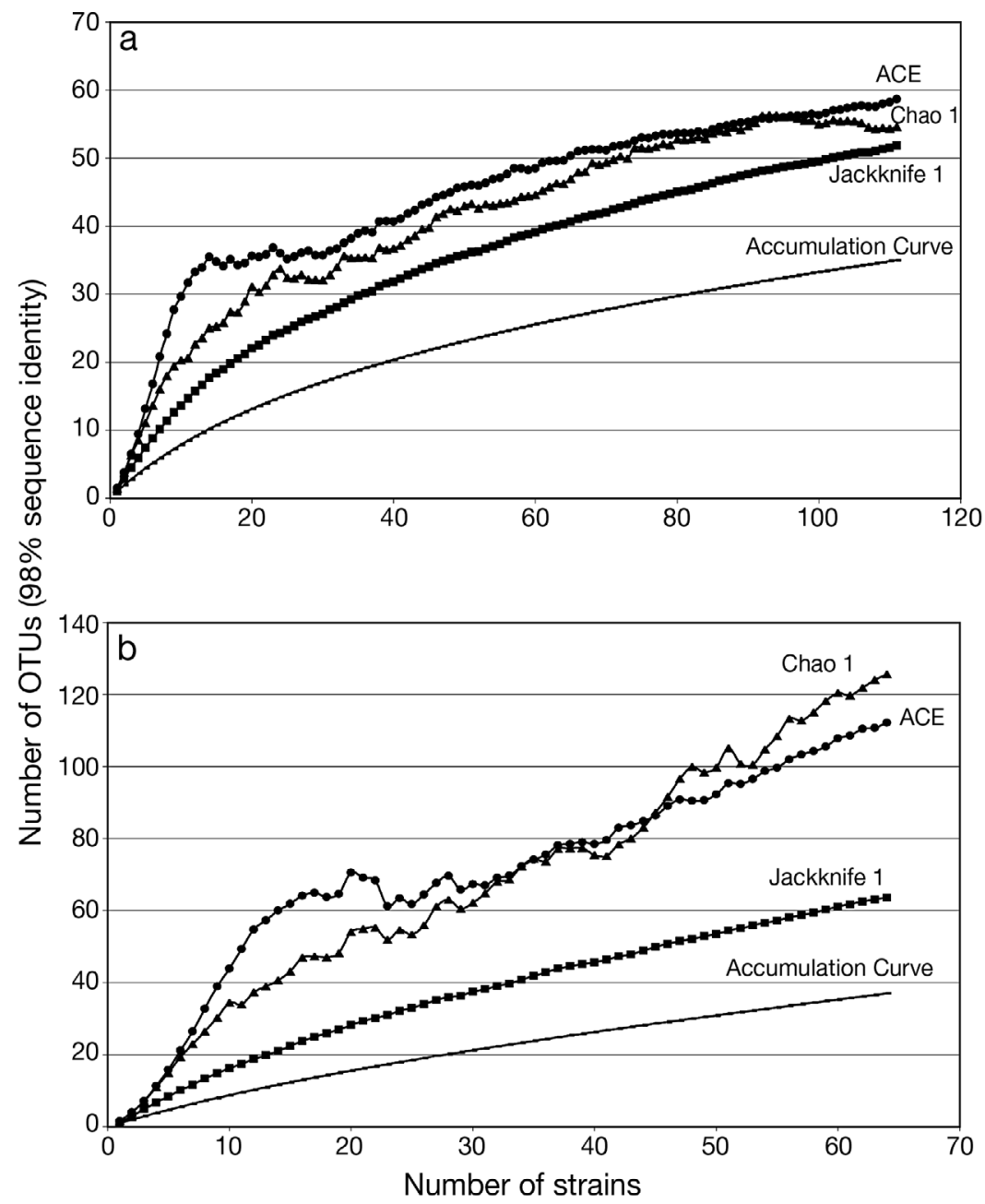

Fig. 3. OTU accumulation curves and diversity estimates calculated using

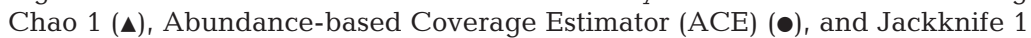
(a) for (a) near-shore and (b) off-shore actinomycete communities

3.4) were approximately equal for both environments, while the Simpson index was considerably greater for the offshore sediments (17.7 vs. 31.5). Although greater diversity is predicted for the off-shore samples, actinomycete colonies were recovered less frequently from this environment, suggesting that accessing this diversity will require the application of additional cultivation procedures.

Rank abundance plots were generated for near- and off-shore communities to assess the richness and evenness of the pool of sequenced strains (Fig. 4). For both analyses, the plots show a long right-hand tail as is typical of highly diverse communities (Hughes et al. 2001), with $50 \%$ or more of the OTUs comprising a single strain. For the nearshore community, $29 \%$ of the strains fell into the 2 most populated OTUs, both of which are most closely related to the genus Streptomyces. One of these (OTU number 2, Fig. 4a) is a 'variable' OTU comprising 5 seawater-dependent and 10 non-seawater-dependent strains. Phylogenetic analysis of all strains within this variable OTU did not delineate seawater-dependent from non-dependent lineages (data not shown). The most populated seawater-dependent OTU (number 4) comprises 7 strains and is most closely related to the genus Nocardiopsis. This OTU was not defined as 'new' or 'marine-specific' using the $98 \%$ sequence identity criterion. The seawater

represented by the 111 strains sequenced. Since all of the strains isolated from the off-shore sediments were sequenced, a coverage calculation was not performed. Accumulation curves were generated and 3 diversity estimators used to predict the total number of OTUs that occur in the near-shore (Fig. 3a) and offshore (Fig. 3b) samples. The non-linearity of the curves reflects well-sampled communities (Martin 2002), and the fact that saturation was not reached in either environment indicates that additional processing would yield more diversity. The diversity estimators Abundance-based Coverage Estimator (ACE), Chao 1, and Jackknife all predict greater diversity in the off-shore $(112.2,125.6,63.4$, respectively) compared to near-shore samples $(58.6,54.6,51.9$, respectively), with the first 2 methods predicting approximately twice as many OTUs off-shore. Species richness (35 vs. 37) and the Shannon index (3.1 vs. requirements of the poorly populated OTUs must be considered tentative until additional strains can be isolated and tested.

When statistical comparisons were made between near- and off-shore communities, the UniFrac measurement was significant $(p=0.01)$ but the P-test was not $(p=0.33)$, suggesting that the phylogenetic distribution of the OTUs is similar for both environments yet the OTUs that comprise them are distinct. When strains from both environments are pooled, 54 OTUs are delineated at the $98 \%$ consensus level (data not shown), with 40 of these being specific to either nearor off-shore sites (20 each). Although these results provide further evidence of differences between the 2 habitats, 13 of the near-shore and 17 of the off-shore specific OTUs are populated by only 1 strain (data not shown), suggesting that these distinctions may be an artifact of small sample size. 


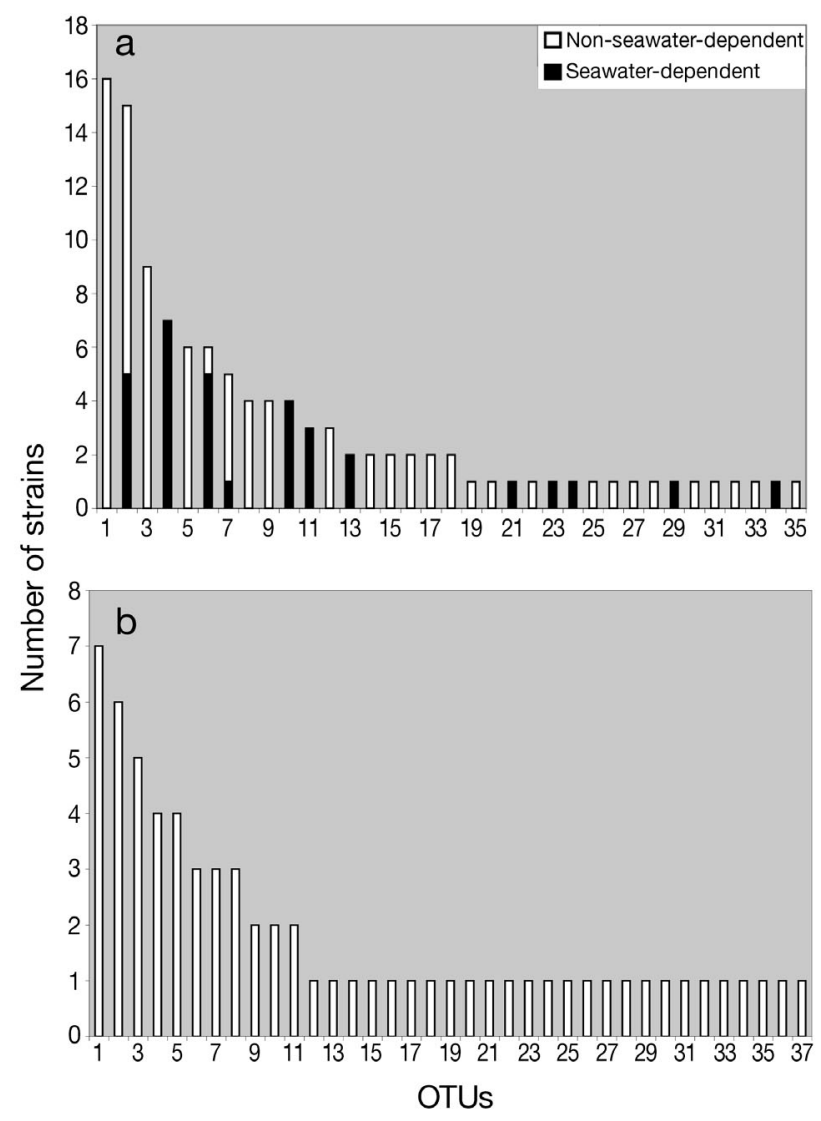

Fig. 4. Rank abundance plots for OTU diversity at $98 \%$ sequence identity from (a) near-shore and (b) off-shore sediments

\section{DISCUSSION}

Actinomycetes are regularly isolated from marine samples (e.g. Maldonado et al. 2005b, Stach \& Bull 2005), yet the extent to which these bacteria are genetically distinct from those recovered from non-marine sources remains unknown. The main objectives of this study were to assess the culture-dependent diversity, phylogenetic novelty, and seawater requirements of filamentous, mycelium-forming actinomycetes cultured from marine sediments collected off the coast of California. These parameters were then compared among strains isolated from near- and off-shore locations to test the hypotheses that marine specificity and the requirement of seawater for growth would be encountered more commonly at sites more distant from shore. In addition, we tested for a correlation between the requirement of seawater for growth and phylogenetic novelty in an effort to determine if this trait could be used to guide the isolation of new marine taxa and to assess the level of marine adaptation in sediment-derived actinomycete communities.
Phylogenetic analyses were performed on 177 strains representing 66 off-shore and 111 near-shore isolates. The near-shore isolates comprised 32 to 40 representatives from each of 3 groups delineated based upon the effects of seawater on growth. In total, actinomycetes related to 8 genera within 6 families were isolated, indicating that considerable actinomycete diversity was recovered from marine sediments including representatives of 5 genera (Nocardiopsis, Actinomadura, Saccharomnospora, Streptosporangium and Verrucosispora) that have seldom been reported from the marine environment.

Various 16S rRNA gene sequence identity values have been used to delineate bacterial OTUs in sequence-based diversity studies (e.g. Hagström et al. 2002). Although the highly conservative value of $97 \%$ has been used in the past, it is now clear that this level of sequence similarity underestimates species-level diversity. For example, it has been shown for Actinobacteria that assigning OTUs based on $>99 \%$ sequence similarity minimized the inclusion of strains with DNA-DNA re-association values of $<70 \%$ and incorporated $70 \%$ of the values $>70 \%$ (Stackebrandt \& Goebel 1994, Stach et al. 2003). To contrast the diversity realized using different sequence identity values, strains were binned into consensus groups over a range from 97 to $100 \%$ similarity (Table 2). These analyses revealed considerable OTU diversity at $99 \%$ sequence identity with 111 near-shore and 66 off-shore strains (Table 1) falling into 44 and 51 OTUs, respectively (Table 2). Comparatively, only 18 near-shore and 16 off-shore OTUs were resolved using $97 \%$ sequence identity. Given the slow rate of change in the $16 \mathrm{~S}$ rRNA gene (Woese 1987), it is likely that less conservative consensus groupings are more accurate predictors of taxonomic diversity in these communities.

For this study, OTUs generated based on 98\% sequence identity were used for statistical analyses and considered 'new' if all of the strains within an OTU shared $\leq 98 \%$ sequence identity with NCBI reference sequences. Using this criterion, new OTUs accounted for 9 of 35 near-shore OTUs and 6 of 37 off-shore OTUs (Table 2). Even when OTUs previously reported from marine sources ('known marine') were considered, the majority of the OTUs detected in this study were previously reported from non-marine sources. Given the relatively high abundance of actinomycetes in soil and the preponderance of material being introduced from land into the sea, it can be suggested that many of these actinomycetes ultimately originated from land. Surprisingly, neither the level of phylogenetic novelty nor marine specificity increased in the off-shore sites (Tables 2 \& 3). There was also no evidence that the San Francisco off-shore site was more highly influenced by terrestrial input despite the fact that a large percent- 
age of California's freshwater drains through the San Francisco Bay estuary relative to San Diego Bay, which is a low inflow estuary. Most of the actinomycete diversity observed in this study was not marine-specific, an observation that could be explained by a high level of terrestrial input and mixing out to $125 \mathrm{~km}$ from shore. This is not to preclude the possibility that higher levels of marine-specific diversity occur at sites more distant from shore and that some marine-specific diversity was missed due to limitations in the culturing techniques employed.

The requirement of seawater for growth was not a common physiological trait among the actinomycetes cultured, being observed in less than $6 \%$ of the strains isolated and 9 of the 54 unique OTUs delineated at $98 \%$ sequence identity. In addition, phylogenetic novelty was not correlated to this requirement, which may in part be due to the $\mathrm{NaCl}$ tolerance of soil actinomycetes (Basilio et al. 2003) or our inability to accurately resolve ecotypes using the 16S rRNA gene (Cohan 2002). The fact that one OTU (represented by strain CNP-966, Fig. 2a) comprised 7 seawater-requiring strains related to the genus Nocardiopsis was not recognized as 'new' or 'marine-specific' suggests that the criteria applied here to delineate marine taxa were overly conservative. It is also possible that the detection of a requirement of seawater for growth is confounded by the rapid loss or acquisition of this phenotype. However, we have not been able to eliminate this requirement following successive transfers onto media prepared with decreasing concentrations of seawater (data not shown), suggesting that this trait is fixed and possibly associated with a specific sodium ion requirement, as has been observed for Gram-negative marine bacteria (Niven \& MacLeod 1980). The seawaterdependent strains cultured from the near-shore collection sites were scattered throughout the phylogenetic tree (Fig. 2a), suggesting that they did not arise from a common marine ancestor and that this trait had instead evolved independently in multiple lineages. Although the requirement of seawater for growth was not common, it was observed among all OTUs related to Nocardiopsis and Streptomonospora, suggesting a high level of marine adaptation in these groups (Fig. 2a).

A deeply rooted marine lineage has been identified within the phylum Actinobacteria (Rappé et al. 1999); however, members of this group have yet to be cultured. As in other cultivation-based studies of actinomycetes in marine sediments (e.g. Pisano et al. 1989, Colquhoun et al. 1998), the dominant genera recovered were Streptomyces and Micromonospora. As has also been previously observed (Weyland 1981, Jensen et al. 1991), there was a shift in community composition from Streptomyces to Micromonospora between near- and off-shore samples (Fig. 2). The cause of this shift remains unresolved as neither OTU novelty, seawater dependence, nor the relative abundance of marine OTUs increased among the off-shore Micromonospora strains. Marine lineages related to the genus Streptomyces however were observed in both near- and off-shore samples. From a phylogenetic perspective, these lineages appear to include multiple new species and represent at least one new genus. Given the breadth of phylogenetic diversity currently ascribed to the genus Streptomyces, revision of this taxon appears warranted.

Fewer actinomycetes were obtained per sample from the off-shore sites despite the fact that the amount of material inoculated was greater and 2 additional media were used. These results suggest that actinomycetes may be less common in the off-shore locations. However, ambient ocean temperatures of $<5^{\circ} \mathrm{C}$ (National Oceanographic Data Center, www.nodc. noaa.gov/) at the shallowest off-shore site in comparison to ca. $15^{\circ} \mathrm{C}$ at the deepest near-shore site suggest that incubation temperatures may have played a role in the relatively low numbers of actinomycetes recovered. Despite the relative difficulty obtaining actinomycetes from the off-shore samples, the number of OTUs delineated from each community was nearly identical (Table 2) and the number of OTUs predicted from the off-shore sites was almost double that from near-shore sediments (Fig. 3).

Remarkably, little redundancy was observed among the cultures as $\geq 75 \%$ of the OTUs delineated at $100 \%$ sequence identity included only 1 strain. The large number of single strain OTUs made it difficult to confidently assign habitat specificity and the effects of seawater on growth. Shannon and Simpson's indices as well as UniFrac statistics (Lozupone \& Knight 2005) show differences between shallow and deep actinomycete communities, supporting the need for further exploration of deep-sea environments, although cultivation at low temperature or high pressure may be required to improve the rate of strain recovery. In summary, phylogenetic novelty and marine specificity were not greater at the off-shore sites, suggesting high rates of mixing out to distances of $125 \mathrm{~km}$ from shore. Nonetheless, considerable new actinomycete diversity was obtained in culture and community diversity was predicted to be greater at the off-shore sites, encouraging continued sampling of deep-sea locations as the bacteria recovered from these sites are proving to be a valuable resource for biotechnology (Bull et al. 2000, Jensen et al. 2005).

Acknowledgements. This work was supported by the Consejo Nacional de Ciencia y Tecnología (pre-doctorate fellowship number 157730 to A.P.-D.) and the NOAA California Sea Grant College Program Project \#R/NMP-98 (Grant \#NA04OAR4170038 to P.R.J.) through NOAA'S National Sea 
Grant College Program, USA Dept. of Commerce. The statements, findings, conclusions and recommendations are those of the author(s) and do not necessarily reflect the views of California Sea Grant or the USA Dept. of Commerce. Additional support came from the NOAA Oceans and Human Initiative (NA05NOS4781249 to P.R.J.). We thank V. KelpacCeraj for providing technical support for the Clusterer program and K. Hardy for design and construction of the untethered coring device. Strains and additional assistance were provided by T. Mincer, O. Aguilar, C. Kauffman, E. Gontang, and E. Kisfaludy. We acknowledge S. Jones, Merkel \& Associates, Inc. for kindly providing the off-shore San Francisco samples and H. Mansfield for his generous assistance with the San Diego collections.

\section{LITERATURE CITED}

Altschul SF, Gish W, Miller W, Myers EW, Lipman DJ (1990) Basic local alignment search tool. J Mol Biol 215:403-410

Basilio A, González I, Vicente MF, Gorrochategui J and others (2003) Patterns of antimicrobial activities from soil actinomycetes isolated under different conditions of $\mathrm{pH}$ and salinity. J Appl Microbiol 95:814-823

Bull AT, Ward AC, Goodfellow M (2000) Search and discovery strategies for biotechnology: the paradigm shift. Microbiol Mol Biol Rev 64:573-606

Bull AT, Stach JEM, Ward AC, Goodfellow M (2005) Marine actinobacteria: perspectives, challenges, future directions. Antonie Leeuwenhoek 87:65-79

Cohan FM (2002) What are bacterial species? Annu Rev Microbiol 56:457-487

> Colquhoun JA, Heald CS, Li L, Tamaoka J and others (1998) Taxonomy and biotransformation activities of some deepsea actinomycetes. Extremophiles 2:269-277

Colwell RK (2004) EstimateS: statistical estimation of species richness and shared species from samples. Version 7. User's guide and application published at: http:// viceroy.eeb.uconn.edu/estimates

Fenical W, Jensen PR (2006) Developing a new resource for drug discovery: marine actinomycete bacteria. Nat Chem Biol 2:666-673

Fiedler HP, Bruntner C, Bull AT, Ward AC and others (2005) Marine actinomycetes as a source of novel secondary metabolites. Antonie Leeuwenhoek 87:37-42

Gontang EA, Fenical W, Jensen PR (2007) Phylogenetic diversity of Gram-positive bacteria cultured from marine sediments. Appl Environ Microbiol 73:3272-3282

Good IJ (1953) The population frequencies of species and the estimation to the population parameters. Biometrika 40 : 237-264

Goodfellow M, Haynes JA (1984) Actinomycetes in marine sediments. In: Ortiz-Ortiz L, Bojalil LF, Yakoleff V (eds) Biological, biochemical and biomedical aspects of actinomycetes. Academic Press, Orlando, FL, p 453-472

Goodfellow M, Williams ST, Mordarski M (1988) Actinomycetes in biotechnology. Academic Press, London

Hagström Å, Pommier T, Rohwer F, Simu K, Stolte W, Svensson D, Zweifel UL (2002) Use of 16S ribosomal DNA for delineation of marine bacterioplankton species. Appl Environ Microbiol 68:3628-3633

Han SK, Nedashkovskaya OI, Mikhailov VV, Kim SB, Bae KS (2003) Salinibacterium amurskyense gen. nov., sp. nov., a novel genus of the family Microbacteriaceae from the marine environment. Int $\mathrm{J}$ Syst Evol Microbiol 53: 2061-2066

Helmke E, Weyland H (1984) Rhodococcus marinonascens sp. nov., an actinomycete from the sea. Int J Syst Bacteriol
$34: 127-138$

Hughes JB, Hellmann JJ, Ricketts TH, Bohannan BJM (2001) Counting the uncountable: statistical approaches to estimating microbial diversity. Appl Environ Microbiol 67: 4399-4406

> Jensen PR, Mafnas C (2006) Biogeography of the marine actinomycete Salinispora. Environ Microbiol 8:1881-1888

Jensen PR, Dwight R, Fenical W (1991) Distribution of actinomycetes in near-shore tropical marine sediments. Appl Environ Microbiol 57:1102-1108

> Jensen PR, Mincer JT, Williams GP, Fenical W (2005) Marine actinomycete diversity and natural product discovery. Antonie Leeuwenhoek 87:43-48

> Lozupone C, Knight R (2005) UniFrac: a new phylogenetic method for comparing microbial communities. Appl Environ Microbiol 71:8228-8235

Magarvey NA, Keller JM, Bernan V, Martin D, Sherman DH (2004) Isolation and characterization of novel marinederived actinomycete taxa rich in bioactive metabolites. Appl Environ Microbiol 70:7520-7529

Maldonado LA, Fenical W, Jensen PR, Mincer TJ and others (2005a) Salinispora gen. nov., sp. nov., Salinispora arenicoal sp. nov., and Salinispora tropica sp. nov., obligate marine actinomycetes belonging to the family Micromonosporaceae. Int J Syst Evol Microbiol 55:1759-1766

Maldonado LA, Stach EMJ, Pathom-aree W, Ward CA, Bull AT, Goodfellow M (2005b) Diversity of cultivable actinobacteria in geographically widespread marine sediments. Antonie Leewenhoek 87:11-18

> Martin AP (2002) Phylogenetic approaches for describing and comparing the diversity of microbial communities. Appl Environ Microbiol 68:3673-3682

Mincer TJ, Jensen PR, Kauffman CA, Fenical W (2002) Widespread and persistent populations of a major new marine actinomycete taxon in ocean sediments. Appl Environ Microbiol 68:5005-5011

> Moran MA, Rutherford LT, Hodson RE (1995) Evidence for indigenous Streptomyces in a marine environment determined with a 16S rRNA probe. Appl Environ Microbiol 61:3695-3700

> Niven DF, MacLeod RA (1980) Sodium ion-substrate symport in a marine bacterium. J Bacteriol 142:603-607

Pisano AM, Sommer JM, Brancaccio L (1989) Isolation of bioactive actinomycetes from marine sediments using rifampacin. Appl Microbiol Biotechnol 31:609-612

Rappé MS, Gordon DA, Vergin KL, Giovannoni SJ (1999) Phylogeny of actinobacteria small subunit (SSU) rRNA gene clones recovered from marine bacterioplankton. Syst Appl Microbiol 22:106-112

$>$ Stach JE, Bull AT (2005) Estimating and comparing the diversity of marine actinobacteria. Antonie Leeuwenhoek 87:3-9

Stach JE, Maldonado LA, Masson DG, Ward AC, Goodfellow M, Bull AT (2003) Statistical approaches for estimating actinobacterial diversity in marine sediments. Appl Environ Microbiol 69:6189-6200

Stach JE, Maldonado LA, Ward AC, Bull AT, Goodfellow M (2004) Williamsia maris sp. nov., a novel actinomycete isolated from the Sea of Japan. Int J Syst Evol Microbiol 54:191-194

Stackebrandt E, Goebel BM (1994) Taxonomic note: a place for DNA-DNA reassociation and 16S rRNA sequence analysis in the present species definition in bacteriology. Int J Syst Bacteriol 44:846-849

Swofford DL (2002) PAUP*. Phylogenetic Analysis Using Parsimony (*and other methods), Version 4. Sinauer Associates, Sunderland, MA 
Takizawa M, Colwel RR, Hill RT (1993) Isolation and diversity of actinomycetes in the Chesapeake Bay. Appl Environ Microbiol 59:997-1002

> Terkina IA, Drukker VV, Parfenova VV, Kostornova TY (2002) The biodiversity of actinomycetes in Lake Baikal. Microbiology 71:346-349

Wang Y, Zhang ZS, Ruan JS, Wang YM, Ali SM (1999) Investigation of actinomycete diversity in the tropical rainforests of Singapore. J Ind Microbiol 23:178-187

Editorial responsibility: Jed Fuhrman,

Los Angeles, California, USA
Weyland H (1969) Actinomycetales in the North Sea and Atlantic Ocean sediments. Nature 223:858

Weyland H (1981) Distribution of actinomycetes on the sea floor. Zentralbl Bakteriol 11:185-193

Woese CR (1987) Bacterial evolution. Microbiol Rev 51:221-271

Yi H, Schuman P, Sohn K, Chun J (2004) Serinicoccus marinus gen. nov., sp. nov., a novel actinomycete with L-ornithine and L-serine in the peptidoglycan. Int J Syst Evol Microbiol 54:1585-1589

Submitted: December 6, 2007; Accepted: May 13, 2008

Proofs received from author(s): June 17, 2008 